\title{
Peter Bimler: uma história de pioneirismo
}

\author{
Dra. Bárbara Bimler*
}

O trabalho do Dr. Bimler (1916-2003) está entrelaçado com o século no qual ele viveu.

No início dos tempos da Ortodontia, durante os séculos 18 e 19, aparelhos fixos feitos de metais preciosos eram o modo mais comuns de tratamento ortodôntico. Em 1881, o desenvolvimento da mola Coffin pelo Dr. Coffin (1853-1916) iniciou o uso de aparelhos removíveis. Pierre Robin (1867-1950) e seu "Monobloco", publicado em 1902, contribuíram mais tarde para sua evolução. Logo após, em 1907, a European Orthodontic Society foi fundada.

Após a Primeira Guerra Mundial (1914-1918), os aparelhos removíveis progrediram mais além. Quando a guerra finalmente terminou, a indústria militar alemã praticamente parou; e companhias como Thyssen e Krupp precisavam desesperadamente de clientes civis e novos mercados. Neste exato momento eles haviam desenvolvido o aço inoxidável. O dentista da clínica da Krupp Company, Dr. F. Hauptmeyer, utilizou o aço com sucesso pela primeira vez em próteses, e a Krupp queria introduzi-lo no mercado dentário como um moderno e econômico substituto para os metais preciosos previamente utilizados. Além disso, eles trabalhavam junto com a estabelecida empresa
Odontológica Renfert. Um de seus mais conhecidos e mais bem sucedidos produtos era chamado "Wipla" - wie Platin que significa "como platina" em alemão. Logo, o novo metal também era utilizado em bandas e arcos na Ortodontia.

Este material econômico para a Odontologia e para a Ortodontia chegou

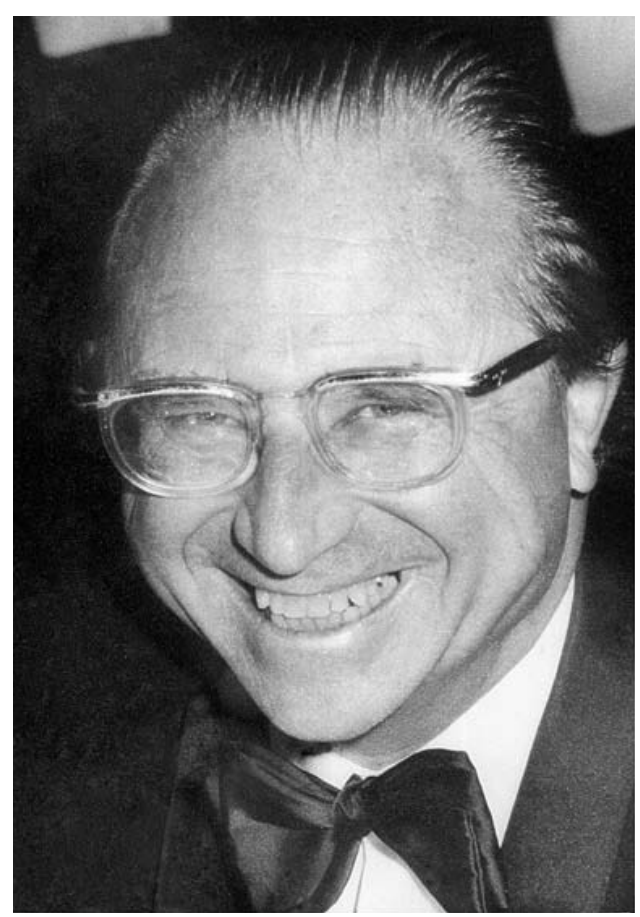
na hora certa para a sociedade em mudança, já que as condições sociais e políticas haviam se desenvolvido rapidamente. A industrialização caminhava juntamente com a reestruturação da sociedade. A classe média e as inferiores ganharam importância política e econômica. Isso se refletiu em seu cuidado com a saúde, incluindo tratamento dentário e ortodôntico.

Um pioneiro no campo da Ortodontia foi Charles Nord de Amsterdã. Ele propagou a correção de "dentes tortos" como tratamento para a população em geral, não mais como um luxo para os ricos. Na reunião da EOS em 1920 em Heidelberg, ele apresentou seus métodos de tratamento para crianças pobres ao preço de cinco florins por mês, aproximadamente cinco dólares.

Isso poderia ser feito apenas com os aparelhos removiveis. Novamente, com grande gerenciamento de tempo, A. Martin Schwarz (1887-1963) de Viena, 
Áustria, apresentou suas placas de expansão em 1936. Isso foi possivel graças a seu técnico que havia desenvolvido um moderno parafuso de expansão. Com o uso do parafuso, o tratamento ortodôntico poderia ser executado por qualquer clínico geral sem educação especial ou treinamento. Outros pioneiros dos aparelhos removiveis foram Viggo Andersen (1870-1950) com seu dispositivo elástico e Karl Häupl (1893-1960). Seus métodos de tratamento foram desenvolvidos e aplicados especialmente na Europa Central e na Escandinávia. Ambos tiveram educação em Medicina Geral e Periodontia, desse modo eles colocavam uma grande ênfase nos aspectos médicos dos aparelhos funcionais removíveis. Ao contrário dos aparelhos fixos, eles não causam dano parcialmente irreversível às raízes, esmalte e periodonto - para não mencionar as articulações? Os aparelhos removiveis logo se tornaram um método de tratamento seguro, econômico e moderno.

Após 1939, durante a Segunda Guerra Mundial, o desenvolvimento na Ortodontia foi interrompido e adiado. Mas a Segunda Guerra Mundial eventualmente também acabou. A vida havia mudado muito, mas também tinha de continuar.

O oficial médico Dr. Peter Bimler retornou em 1946 de um campo britânico de prisioneiros de guerra para a Alemanha. Ele encontrou seu primeiro emprego como médico assistente de seu tio, um especialista otorrinolaringologista. Logo ele considerou tornar-se um cirurgião plástico. Seu prático pai, entretanto, convenceu-o de que havia muitos cirurgiões plásticos procurando por novas ocupações, enquanto havia poucos ortodontistas, e estes eram extremamente necessários após a guerra. Então, o Dr. Bimler estudou Odontologia num programa especial para médicos e se tornou parceiro na prática ortodôntica de seu pai, que começou praticamente do zero, já que agora eles eram refugiados, restabelecendo-se na Alemanha Ocidental.

A economia desintegrada do pós-guerra na Alemanha requeria de pai e filho um alto nivel de inspiração e criatividade. O pouco suprimento de material odontológico disponível era muito caro para eles. Felizmente, o pai, Dr. Walter Bimler, havia salvado alguns rolos de aço inoxidável, e desse modo, seu fi- 1ho Peter gastou seu tempo livre para desenvolver seu próprio aparelho ortodôntico, para ser independente dos materiais e preços dos outros.

A principal preocupação além do aspecto econômico era a eficiência. Bimler queria combinar a eficiência do tratamento fixo com a segurança dos removíveis. O formato final do Adaptador Oral, "Gebissformer", foi resultado de vários anos de experiência clínica com diferentes formatos, variações e fios. Até o dia de hoje, o aparelho é utilizado no mundo todo como foi originalmente desenvolvido.

Para Bimler, era muito importante que a língua se movesse facilmente e que a fala do paciente não fosse impedida, desse modo eles poderiam usar o aparelho o dia todo, inclusive na escola. Ele estava muito satisfeito com o rápido progresso de seus pacientes. Como as crianças geralmente são honestas, às vezes elas confessavam que usavam o aparelho apenas à noite. Apesar disso, alguns anos de experiência e observação clínica foram necessários para confirmar que as crianças estavam corretas; de fato, a observação clínica provou que o período noturno era suficiente para o tratamento. Portanto, o Aparelho Bimler, como logo ficou conhecido, podia oferecer a maior vantagem para o conforto do paciente: Corrige seus dentes enquanto você dorme!

Naquela época, havia apenas aproximadamente 40 especialistas em Ortodontia na Alemanha Ocidental. Eles não conseguiam de modo algum atender todos os pacientes. Para facilitar o cuidado ortodôntico para a maior parte possível da população, Peter Bimler fundou em 1953 o "Bimler Laboratorien KG" e estabeleceu uma "Orto-Clínica" seguindo a idéia da Clínica Mayo Norte Americana. O conceito era de que clínicos gerais iriam realizar o tratamento ortodôntico e consultar o especialista em qualquer caso de dúvida ou problemas. Eles enviariam os modelos e outros documentos e receberiam o plano de tratamento, o aparelho, coberto por suporte e conselhos telefônicos. Isto funcionou bem por muitos anos até haverem suficientes ortodontistas especializados disponíveis.

Não apenas na Alemanha Ocidental mas também no exterior, o Aparelho Bimler se tornou rapidamente muito popular. Apenas o desenvolvimento e a 
introdução de partes pré-fabricadas, arcos e molas já prontos em diferentes tamanhos possíveis, poderiam satisfazer a demanda mundial. Com as peças pré-fabricadas, não-técnicos também poderiam rapidamente aprender a montar corretamente um Aparelho Bimler. Estas peças pré-fabricadas se tornaram um grande sucesso e são vendidas no mundo todo até hoje.

Com todos esses sucessos satisfatórios, também houve decepções. Nem todos os pacientes se desenvolviam de acordo como o esperado. Por que? Como poderia o mesmo aparelho e o mesmo tratamento algumas vezes desenvolver respostas tão diferentes?

Anteriormente, o Dr. Bimler havia feito a mesma pergunta, durante a sua época na Otorrinolaringologia: Por que a cirurgia para retirada das amídalas ajuda alguns dos respiradores bucais, tão dramaticamente e maravilhosamente, e não apresentam quase nenhum efeito para outros?

Comparando a radiografia da cabeça dos pacientes afetados, havia certos padrões esqueléticos, que estavam relacionados ao sucesso e ao fracasso. Com base nisso, o Dr. Bimler desenvolveu sua análise cefalométrica com o intuito de descobrir por ele mesmo uma explicação para as diferentes reações de seus pacientes aos diferentes métodos de tratamento.

Com base nas suas experiências da clínica de Otorrinolaringologia, Bimler primeiramente direcionou sua atenção à parte do assoalho Nasal e ao Plano Mandibular. Nas publicações iniciais, três planos de investigação foram mencionados, e eventualmente outras estruturas esqueléticas foram incorporadas. Em 1957, o primeiro relato das "Análises de fatores" foi publicado com 10 "Fatores" representando as relações esqueléticas.

Durante o verão de 1967, Robert Ricketts visitou a Alemanha Ocidental com sua família e comparou notas científicas. Em suas próprias análises, ele deu sua interpretação da nomenclatura anatômica, desse modo "dolicofacial" significa o contrário de "dolicoprosópico" anatômico, que é o contrário de leptoprosópico. Como a versão de Ricketts era geralmente aceita na Odontologia, Bimler preferiu para a descrição dos tipos faciais as palavras horizontal e vertical, que são claramente definidas e internacionalmente entendidas.
A aplicação clínica da análise e a experiência diária com o passar dos anos e das décadas trouxeram algumas mudanças, como no uso dos aparelhos. Nos anos 80, Bimler reuniu as mensurações mais informativas em uma "Análise Compacta". O código de cores adicional permite uma rápida avaliação das estruturas esqueléticas e as possibilidades e limitações de um tratamento, na primeira visualização.

A Análise de Bimler ignora valores médios e de norma. Valores e normas estatísticas foram originalmente desenvolvidos pelas companhias de seguro de vida para calcular as recompensas e contribuições. Mas nós sabemos bem que nossa morte ocorrerá independentemente dos valores estatísticos médios. O mesmo é verdade para todos os valores médios estatísticos e sua relação com o indivíduo. Entretanto, o sucesso duradouro de um tratamento ortodôntico depende da harmonia da estrutura esquelética, dos dentes e do tecido mole, e não de sua relação com os valores estatísticos médios.

Os resultados da análise cefalométrica ajudam com o prognóstico e servem para explicar falha ou sucesso. Para o diagnóstico de uma má oclusão e a construção do aparelho, apenas os modelos de gesso e o registro da mordida patológica são necessários.

Desde alguns anos, grupos de estudo locais para o tratamento, Análise e filosofia Bimler começaram a se formar. Agora estamos trabalhando para interconectá-los. Os endereços podem ser encontrados no site www.bimler.com. Alguns dos participantes possuem muitos anos de experiência prática em Bimler e estão prontos para dividi-la com você.

* Nesse número da Revista Dental Press, a seção História da Ortodontia foi enriquecida pela participação da Dra. Daisy Saraiva que solicitou à Dra. Bárbara Bimler, filha de Peter Bimler, o envio do conteúdo aqui disposto. A Dra. Daisy é uma das componentes do Grupo de Estudos de Bimler do qual também fazem parte os seguintes profissionais: Alcibíades Gonzáles, da Argentina; Derek Mahony, da Austrália; Michael Champagne, do Canadá; Luis Alfonso Murillo, da Costa Rica; Luis Soto, de Cuba; Arno Geis, da Alemanha; Masaru Iwatsuki, do Japão; Irma Oviedo, do México; Angeles Vicente, da Espanha e Tom Graber dos EUA. 